\title{
TRÊS NOVAS ESPÉCIES DE MEMBRACIDAE (HOMOPTERA) ${ }^{1}$
}

\author{
Antonio José Creão-Duarte ${ }^{2}$ \\ Albino M. Sakakibara ${ }^{3}$
}

\begin{abstract}
Three new species of Membracidae (Homoptera). Ennya scaramozzinoi, sp.n. from Ecuador, Calloconophora dietrichi, sp.n. and Amastris deitzi, sp.n., both from Mato Grosso, Brazil, are deseribed.

KEY WORDS. Ennya, Calloconophora, Amastris, Homoptera, Membracidae
\end{abstract}

\section{Ennya scaramozzinoi, sp.n.}

Fig. $1(\mathrm{a}-\mathrm{e})$

Caracteres diagnósticos. Pronoto de coloração geral amarelo pálida, com manchas pretas nos espaços entre as carenas. Processo dorsal subcônico, vertical. Processos para-umerais triangulares, projetados lateralmente.

Medidas (mm) fềmea/macho. Comprimento do pronoto: 9,00/8, 17. Distância entre os processos para-umerais: 4,50/4,25. Largura da cabeça: 3,00/2,83.

Descrição holótipo fềmea. Cabeça triangular mais larga que longa, com quatro pontos pretos: dois junto à margem superior do vértice, na direção dos ocelos e dois circundando os ocelos. Olhos semi-globulares. Ocelos equidistantes entre si e dos olhos, situados sobre a linha imaginária que passa pelo centro dos mesmos. Clípeo, em vista frontal em forma de losango, com uma mancha preta em forma de $\mathbf{V}$ invertido.

Pronoto com pontuação grossa, de coloração geral amarelo-pálida, tendo nos dois terços anteriores manchas pretas irregulares entre as carenas, sobre as impressões musculares e sobre o metopídio, estendendo-se até o ápice do processo dorsal; mancha preta pré-apical cobrindo as carenas. Processo dorsal subcônico, vertical, localizado bem atrás dos úmeros. Processo posterior tectiforme, acuminado, alcançando a extremidade das tégminas. Processos para-umerais triangulares, projetados lateralmente, com uma pequena mancha preta no ápice.

Tégminas escuras, com textura semelhante à do pronoto nos dois terços basais da porção exposta; igualmente manchadas de preto entre as veias. Com cinco células apicais, a terceira peciolada, e uma célula discoidal. Asas hialinas, com quatro células apicais, a segunda peciolada; lóbulo jugal distinto.

1) Contribuição número 793 do Departamento de Zoologia. Universidade Federal do Paraná.

2) Departamento de Sistemática e Ecologia. Universidade Federal da Paraỉa, 58059-900 João Pessoá, Paraiba, Brasil.

3) Departamento de Zoologia. Universidade Federal do Paraná, Caixa Postal 19020, 81531-970 Curitiba, Paraná, Brasil. 
Tórax, coxas e abdome escuros, pernas amareladas. Tíbias III com cuculos setíferos nas arestas I e II. Basitarsos III com duas fileiras de cuculos setíferos.

Macho muito parecido com a fêmea, porém menor e mais escuro, com as manchas sobrepondo as carenas pronotais.
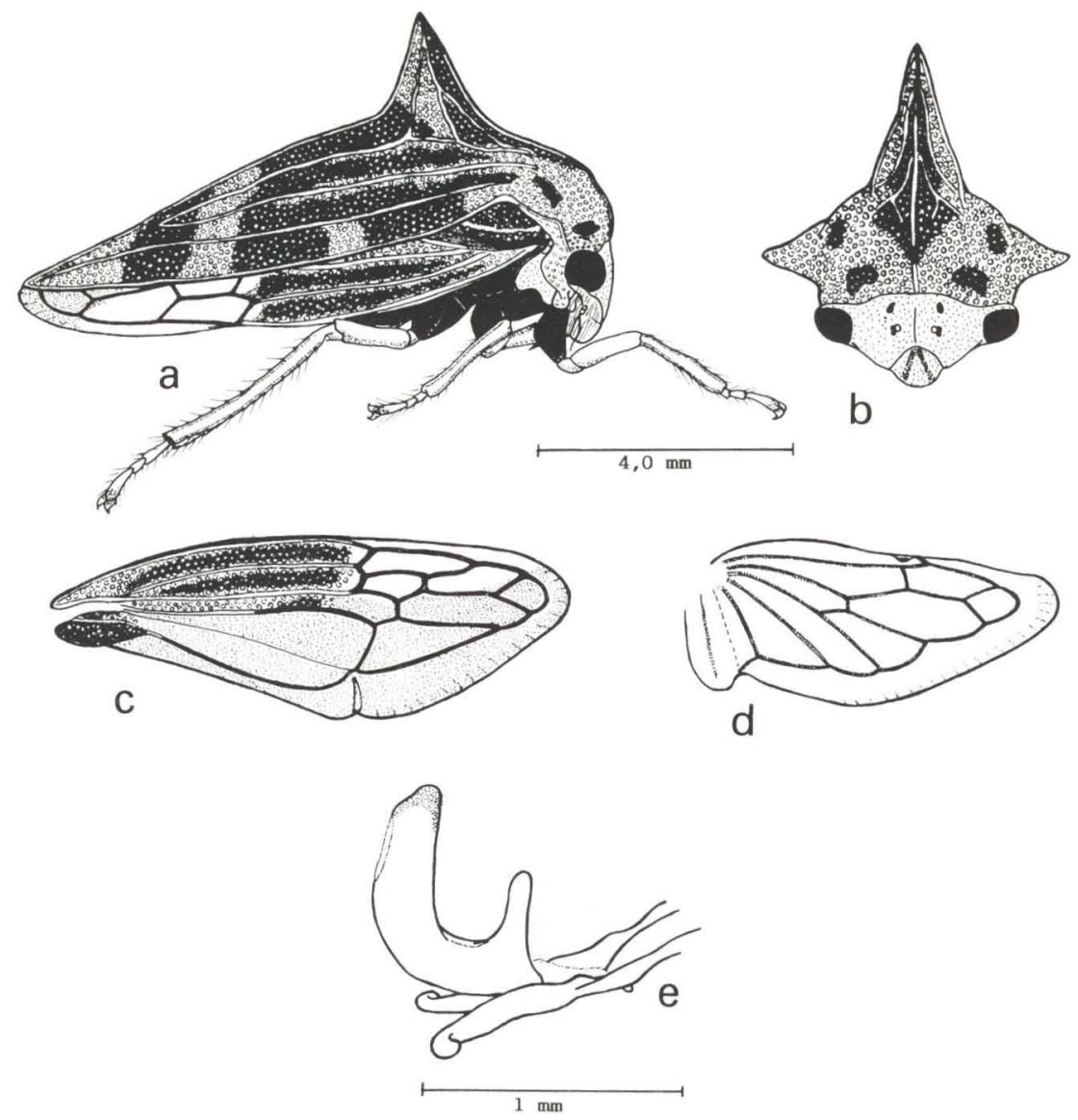

Fig. 1. Ennya scaramezzinoi, sp.n. parátipo. (a) Vista lateral: (b) vista frontal; (c) tégmina dircita; (d) asa posterior direita; (e) edeago.

Holótipo fềmea de "Ecuador; La Mana; XII.19.81; leg. G. Onore". Parátipos: 24 fềmeas e três machos com os mesmos dados do holótipo. Parátipo fêmea de "Ecuador; Las pampas; VIII.1981; leg. G. Onore". Depositados na Coleção do Museu Regional de Ciências Naturais de Torino, Itália, exceto quatro parátipos (duas fềmeas e dois machos) na Coleção de Entomologia Pe. Jesus Santiago Moure, Departamento de Zoologia, Universidade Federal do Paraná (DZUP). 
Comentários. Esta espécie, no aspecto geral, aproxima-se de E. chrysura Fairmaire, 1846, diferindo da mesma pela coloração do pronoto (amarelo pálido, com os espaços entre as carenas enegrecidos). Nos machos, em geral, a cor negra predomina, como acontece em E. chrysura. O pronoto apresenta somente uma elevação cônica, pontiaguda, localizada bem atrás dos úmeros.

O nome da espécie em homenagem ao Dr. Pier Luigi Scaramozzino, que nos tem permitido o estudo dos membracídeos do Museu de Ciências Naturais de Torino, Itália.
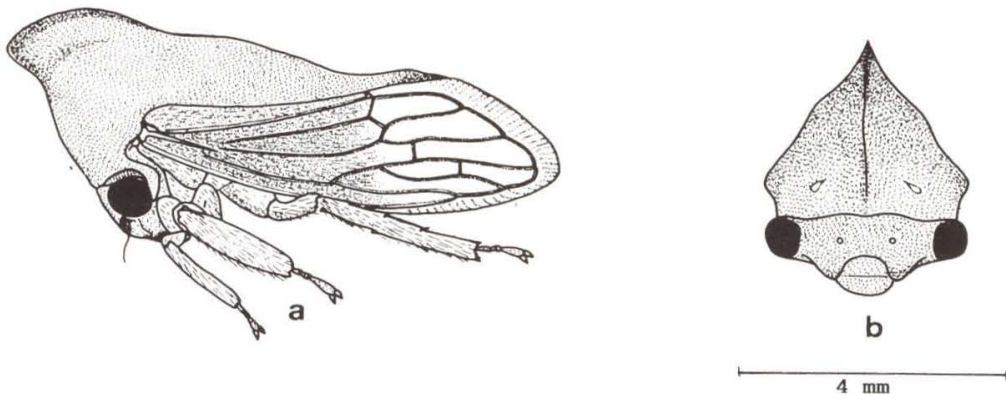

$4 \mathrm{~mm}$
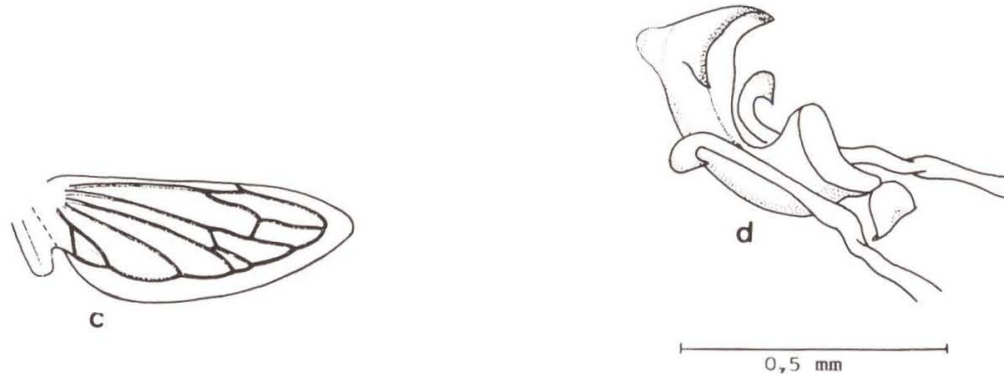

Fig. 2. Calloconophora dietrichi, sp.n. holótipo. (a) Vista lateral; (b) vista frontal; (c) asa posterior direita; (d) edeago.

\section{Calloconophora dietrichi, sp.n.}

Fig. 2 (a-d)

Caracteres diagnósticos. Pronoto de coloração geral castanho escura, pubescente, com processo anterior curto e obtuso.

Medidas (mm) fêmea/macho. Comprimento do corpo: 9,00/8,83. Comprimento do pronoto: $7,42 / 6,75$. Distância entre os processos para-umerais: 3,58/3,33. Largura da cabeça: 3,42/3,08.

Descrição holótipo macho. Cabeça triangular mais larga que longa. Olhos semiglobulares. Ocelos equidistantes entre si e dos olhos, situados sobre a linha imaginária que passa pelo centro dos mesmos. Clípeo achatado e dobrado para trás, com uma carena transversal medianamente. 
Pronoto com pontuação fina, densamente pubescente; linha de contorno superior sinuosa; carena mediana quase imperceptível. Processo anterior curto e obtuso com a ponta ligeiramente inclinada para baixo. Processo posterior acuminado com a extremidade ligeiramente curvada para cima, terminando quase junto ao ápice da quinta célula apical.

Tégminas coriáceas, pontuadas e pubescentes na metade basal e depois transparentes e corrugadas. Cinco células apicais e uma discoidal. Asas hialinas com quatro células apicais, a quarta muito pequena; lóbulo jugal distinto.

Tórax, e pernas castanho escuros. Tíbias I e II subfoliáceas. Tíbias III com cuculos setíferos nas arestas I e II. Abdome castanho.

Macho semelhante à fêmea, porém um pouco menor.

Holótipo macho de "Sinop-Mato Grosso-Brasil; X.1976; M. Alvarenga". Parátipos: dois machos e uma fêmea , com os mesmos dados do holótipo, depositados na Coleção de Entomologia Pe. Jesus Santiago Moure (DZUP).

Comentários: Comparando $C$. dietrichi com os desenhos apresentados por Dietrich \& Deitz (1991), observa-se que esta espécie aproxima-se de $C$. subinermis (Stål, 1862) pela forma do processo anterior. Entretanto, difere quanto ao aspecto do edeago, que apresenta a corona destituída de dentículos e margem lateral pronunciada.

O nome da espécie em homenagem ao Dr. Christopher H. Dietrich.

\section{Amastris deitzi, sp.n.}

Fig. 3

Caracteres diagnósticos. Pronoto liso, com pontuações diminutas, de coloração geral alaranjada, com manchas brancas irregulares ; mais elevado acima dos úmeros e ligeiramente inclinado para frente.

Medidas (mm) fêmea/macho. Comprimento do pronoto: 4,12/3,44. Distância entre os processos para-umerais: 1,56/1,52. Largura da cabeça: 1,48/1,40.

Descrição holótipo fêmea. Cabeça triangular, um pouco mais larga que longa, ligeiramente pontuada. Olhos globulares. Ocelos equidistantes entre si e dos olhos, situados sobre a linha imaginária que passa pelo centro dos olhos. Clípeo subtriangular com carena mediana distinta.

Pronoto de contorno superior largamente arqueado, mais elevado acima dos úmeros, levemente inclinado para frente, formando com a linha do metopídio um ângulo pouco menor que $90^{\circ}$; posteriormente acuminado, terminando junto com o ápice das tégminas; superfície brilhante e praticamente lisa, com pontuações muito finas; coloração geral alaranjada com manchas irregulares, formadas por pontos brancos coalescentes. Processos para-umerais pouco salientes.

Tégminas transparentes, coriáceas na base; cinco células apicais, a terceira peciolada, com o ramo $\mathrm{M}_{1+2}$ bem mais longo que $\mathrm{R}_{4+5}$. Asas hialinas com quatro células apicais.

Tórax e pernas amarelados. Tíbias III com cuculos setíferos nas arestas I, II e III. Basitarsos III com duas fileiras de cuculos setíferos. Abdome amarelado. 


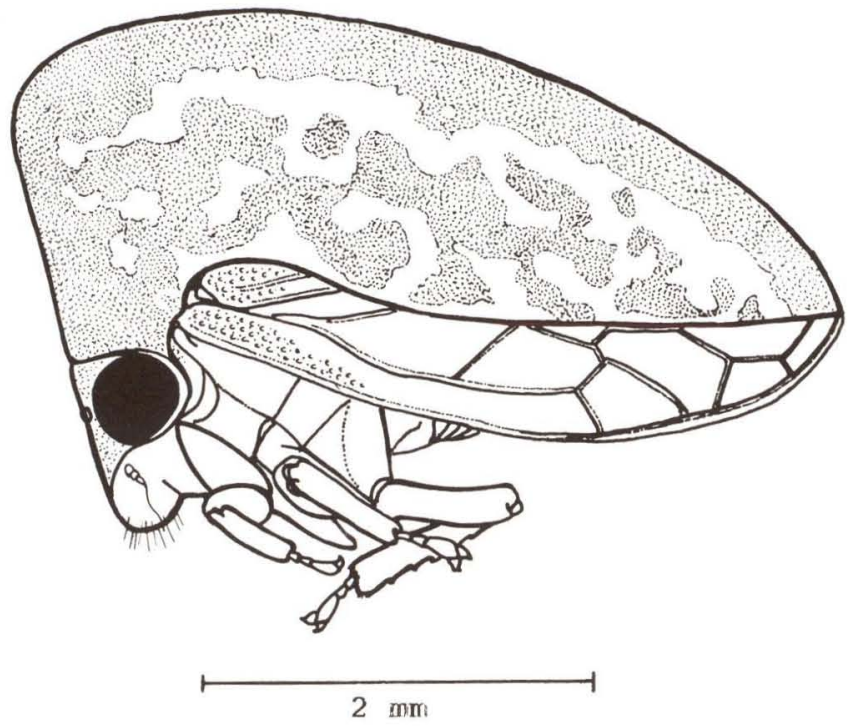

Fig. 3. Amastris deitzi, sp.n. holótipo.

Macho semelhante à fêmea, porém menor.

Holótipo fêmea de "Sinop-Mato Grosso-Brasil; X.1976; M. Alvarenga". Parátipos um macho e uma fêmea com os mesmos dados do holótipo, depositados na Coleção de Entomologia Pe. Jesus Santiago Moure (DZUP).

Comentários: Comparando Amastris deitzi com as descrições e desenhos apresentados por BRoOMFIELD (1976), observa-se que esta espécie, pela forma do pronoto, aproxima-se de $A$. compacta (Walker, 1858). A pigmentação do pronoto é semelhante à de A. gutatta Fonseca, 1941 e A. viridisparsa Broomfield, 1976.

O nome da espécie em homenagem ao Dr. Lewis L. Deitz.

\section{REFERÊNCIAS BIBLIOGRÁFICAS}

Broomfield, P.S. 1976. A revision of the genus Amastris (Homoptera: Membracidae). Bull. British Mus. (Natural History) Entomol. 33 (4): 349-460. Dietrich, C.H \& L.L. Deitz. 1991. Revision of the Neotropical Treehopper Tribe Aconophorini (Homoptera: Membracidae). North Carolina Agricultural Research Service Tech. Bull. 293: 1-134. 